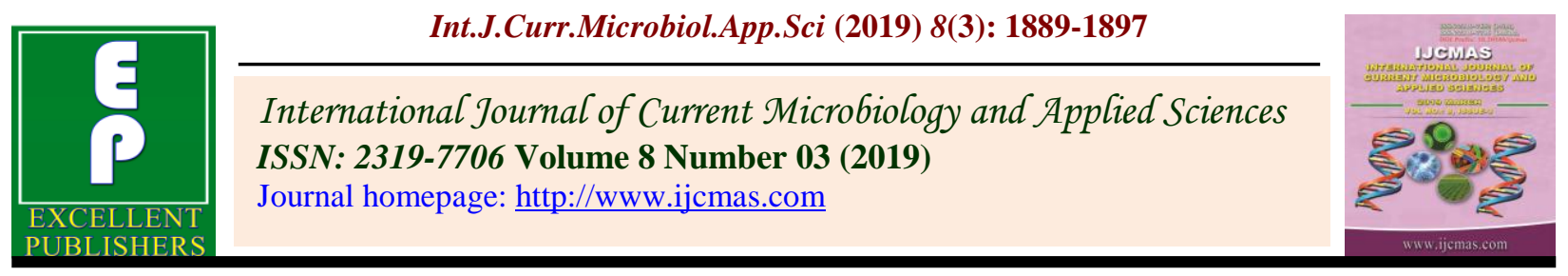

Review Article

https://doi.org/10.20546/ijcmas.2019.803.224

\title{
Pesticides Classification and its Impact on Environment
}

\author{
Rajveer Kaur $^{1 *}$, Gurjot Kaur Mavi ${ }^{2}$ and Shweta Raghav ${ }^{3}$ \\ ${ }^{1}$ School of Animal Biotechnology, ${ }^{2}$ Department of Animal Genetics and Breeding, \\ ${ }^{3}$ Department of Veterinary Anatomy, Fisheries, Guru Angad Dev Veterinary and Animal \\ Sciences University, Ludhiana-141004(Punjab), India \\ *Corresponding author
}

A B S T R A C T

Keywords

Pesticides, WHO

classification,

Environment,

Toxicity

Article Info

Accepted:

15 January 2019

Available Online:

10 February 2019
Pesticides are substance or mixture of substance which differ in their physical, chemical and identical properties from one to other. Hence, they are classified based on these properties. Some pesticides are also categorized into various classes depending on the needs. Presently, three most popular classifications of pesticides which are widely used is classification based on the mode of entry, pesticide function and the pest organism they kill, the chemical composition of the pesticide. Based on toxicity of pesticides, WHO classified them into four classes: extremely dangerous, highly dangerous, moderately dangerous and slightly dangerous.

\section{Introduction}

Environmental pollution is a global phenomenon and the risks and outcomes on human health are a worrying factor. The present situation of pollution is a man-made calamity though the fact of benefit-risk ratio also needs to be weighed equally before complaining on the issue of pollution. Pesticides are designed to kill and because their mode of action is not specific to one species, they often kill or harm organisms other than pests, including humans. The WHO estimates that there are 3 million cases of pesticide poisoning each year and up to 220,000 deaths, primarily in developing countries. Pesticides results in production of reactive oxygen species which in turn brings down the antioxidant levels and their defense against oxidative damage in the cellular system. Lipids, proteins and nucleic acids are targeted due to the imbalance and cellular signalling pathways are affected. Oxidative stress and reactive oxygen species induce the long-term health effects such as carcinogenesis, neuro-degeneration, cardiovascular, respiratory, renal, endocrine and reproductive problems. When pesticides disturb the oxidative balance, they pave way for these diseases and homeostasis. The application of pesticides is often not very precise. As the contribution of agro-chemicals towards increasing agricultural production is well established, however, it may causes 
damage to the environment; the ecosystem including the mankind. Pesticides are known to control insect pests, weeds, diseases, rodents and pests in the storage. Though the pesticide industry in the developed world has made good progress in the field of development and production of low risk/low volume user and environment friendly pesticides formulation, pesticides in the developing countries still now are mainly available in conventional formulations such as dust, wettable powder, emulsifiable concentrates and solutions etc. As pesticides are responsible for several adverse effects on human health other than acute intoxications. Many studies have reported associations between exposure to agricultural chemicals and various health outcomes, including different kinds of cancer (Daniels et al., 1997, Khuder and Mutgi, 1997; Zahm and Ward, 1998) and degenerative diseases (Engel et al., 2001; Jenner, 2001). Effects in immune, hematological, nervous, endocrine and reproductive systems have been reported (Ojajarvi et al., 2000; Ritz and Yu, 2000; Figa-Talamanca and Petrelli, 2001; Mourad, 2005) and these compounds have been also associated with DNA damage in human populations (Gomez-Arroyo et al., 2000; Undeger and Basaran, 2002; Costa et al., 2007; Ergene et al., 2007; Muniz et al., 2008). Exposure to low-level of pesticides is known to produce a variety of biochemical changes, some of which may be responsible for the adverse biological effects reported in human and experimental studies (Gupta et al., 1998; Banerjee et al.,1999; Panemangalore et al., 1999). Conversely, some biochemical alterations may not necessarily lead to clinically recognizable symptoms, although all the biochemical responses can be used as markers of exposure or effect (Panemangalore et al., 1999).

Pesticides are used to kill the pests and insects which attack on crops and harm them.
Different kinds of pesticides have been used for crop protection for centuries. Pesticides benefit the crops; however, they also impose a serious negative impact on the environment. Excessive use of pesticides may lead to the destruction of biodiversity. Many birds, aquatic organisms and animals are under the threat of harmful pesticides for their survival. Pesticides are a concern for sustainability of environment and global stability. This chapter intends to discuss about pesticides, their types, usefulness and the environmental concerns related to them. Pollution as a result to overuse of pesticides and the long term impact of pesticides on the environment.

A pesticide is a toxic chemical substance or a mixture of substances or biological agents that are intentionally released into the environment in order to avert, deter, control and/or kill and destroy populations of insects, weeds, rodents, fungi or other harmful pests. Pesticides work by attracting, seducing and then destroying or mitigating the pests. Pests can be broadly defined as the plants or animals that jeopardize our food, health and / or comfort. The use of pesticides has increased many folds over the past few decades. According to an estimate, about 5.2 billion pounds of pesticides are used worldwide per year. The use of pesticides for pest mitigation has become a common practice all around the world. Their use is not only restricted to agricultural fields, but they are also employed in homes in the form of sprays, poisons and powders for controlling cockroaches, mosquitoes, rats, flea s, ticks and other harmful bugs.

\section{Pesticide use}

In 1600s, a mixture of honey and arsenic was used for controlling ants. In late 1800s, farmers in the USA started using certain chemicals such as nicotine sulphate, calcium arsenate and sulphur for field related posts; 
however; their efforts were unfruitful because of the primitive methods of application (Delaplane, 2000). In 1867, an impure form of copper, arsenic was used to control the outbreak of Colorado potato beetle in the USA (History of pesticide use 1998). The major breakthrough in pesticide development occurred in the period around and after World War-II, when several effective and inexpensive pesticides were synthesised and produced. This period is marked by the discovery of Aldrin, dichlorodiphenyl trichloroethane (DDT) in 1939, Dieldrin, $\beta$ Benzene Hexachloride (BHC), 2,4Dichlorophenoxyacetic acid (2,4-D), Chlordane and Endrin (Jabbar and Mallick 1994; Delaplane, 2000). It has been observed that the overuse of pesticides on aquatic ecosystems has led to a serious threat to species of fi sh including salmon. Pesticides are also seen to affect primary producers and macro-invertebrates (Macneale et al., 2010). In Pakistan, before 1980, Plant Protection Department of Government of Pakistan was responsible for the import and distribution of pesticides. Pesticide purchase was on prepayment basis and there was also subsidy on it. However, in 1980, this responsibility was passed on to the private sector. Since that time, there has been a steady increase in pesticide import and consumption in Pakistan. Registration of a pesticide is renewed sporadically, which ensures the safety of used pesticides (Jabbar and Mallick, 1994). Currently, preference is given to biological control of pests. This is a bioeffector method of controlling pests using biocontrolling agents including other living organisms. These biocontrolling agents are also known as bio-rational pesticides. An example of biorational pesticide is Insect growth regulators (IGRs).

\section{Toxicological classification of pesticides}

Pesticide is a common term that characterizes several classes of insecticides, herbicides, fungicides, rodenticides, wood preservatives, garden chemicals and household disinfectants that are used to either to kill or protect from pests. These pesticides differ in their physical, chemical and identical properties from one class to other. Therefore, it is worthy to classify them based their properties and study under their respective groups. Synthetic pesticides are manmade chemicals, and do not occur in nature. They are categorized into various classes depending on the needs. Presently, there are three most popular method of pesticides classification suggested by Drum. These three popular methods of pesticides classes comprises: (i) classification based on the mode of entry, (ii) classification based on pesticide function and the pest organism they kill, and (iii) classification based on the chemical composition of the pesticide

\section{Classification of pesticides}

The most common and useful method of classifying pesticide is based on their chemical composition and nature of active ingredients. It is such kind of classification that gives the clue about the efficacy, physical and chemical properties of the respective pesticides. The information on chemical and physical characteristics of pesticides is very useful in determining the mode of application, precautions that need to be taken during application and the application rates. Based on chemical composition, pesticides are classified into four main groups namely; organochlorines, organophosphorus, carbamates and pyrethrin and pyrethroids. The chemical based classification of pesticides is rather complex. In general, modern pesticides are organic chemicals. They include pesticides of both synthetic and plant origin. However, some inorganic compound is also used as pesticides. Insecticides are important pesticides that can be further classified into several sub-classes (Fig. 1). 
Fig.1

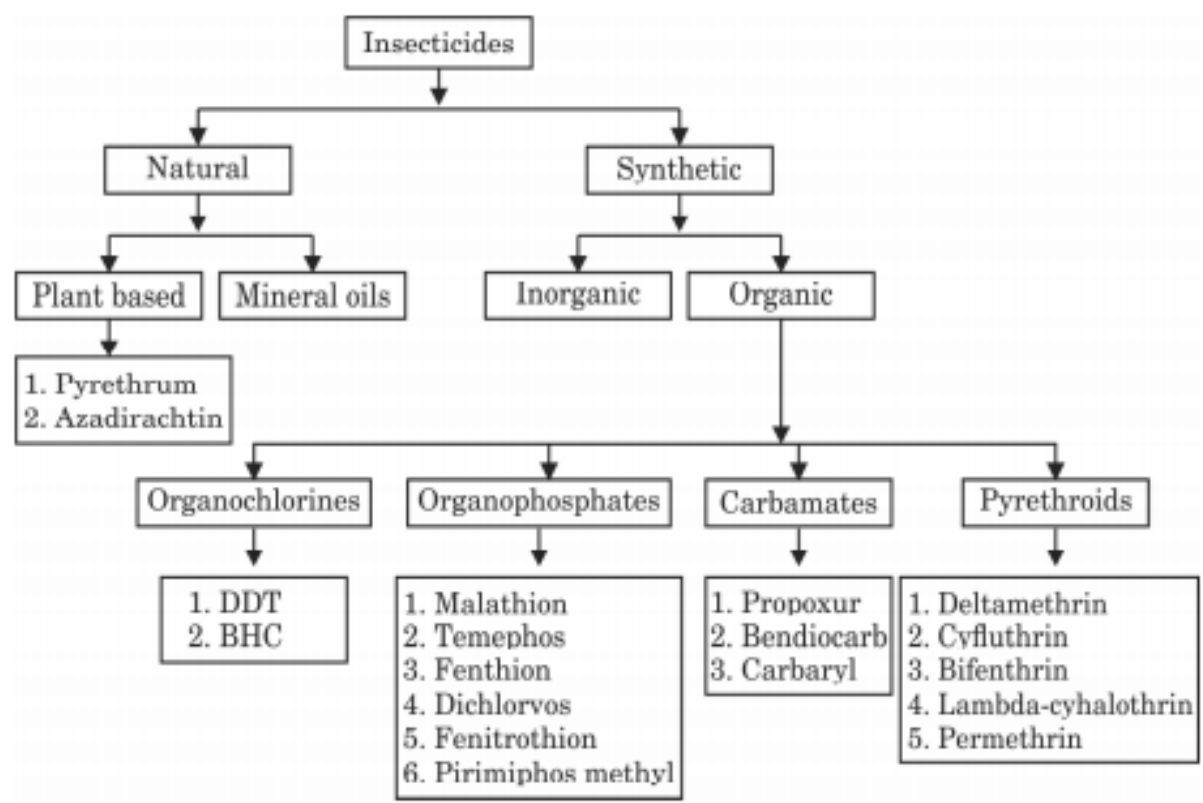

\section{Organochlorine}

Organophosphate pesticides are considered to be one of the broad spectrum pesticides which control wide range of pests due to their multiple functions. They are characterized with stomach poison, contact poison and fumigant poison leading to nerve poisons. These pesticides are also biodegradable, cause minimum environmental pollution and are slow pest resistance. Organophosphorus insecticides are more toxic to vertebrates and invertebrates as cholinesterase inhibitors leading to a permanent overlay of acetylcholine neurotransmitter across a synapse. As a result, nervous impulses fail to move across the synapse causing a rapid twitching of voluntary muscles, hence, leading to paralysis and death.

\section{Carbamates}

Carbamates are similar to organophosphates. However, they differ in their origin. Organophosphates are derivatives of phosphoric acid, while carbamates derived from carbamic acid. The working principal of carbamate pesticides is similar to organophosphate pesticides by affecting the transmission of nerve signals resulting in the death of the pest by poisoning. Sometimes, they are also used as stomach and contact poisons as well as fumigant. They can be easily degraded under natural environment with minimum environmental pollution. Some of the widely used insecticides under this group include carbaryl, carbofuran, propoxur.

\section{Fipronil}

Fipronil is an insecticide of the phenylpyrazoles class and an active ingredient of one of the popular ectoparasiticide veterinary products, Frontline. Frontline is commonly used on dogs and cats to kill fleas, and all stages of ticks (brown dog ticks, American dog ticks, lone star ticks) which may carry Lyme disease, and mites. Fipronil is also formulated as insect bait for roaches, ants, and termites; as a spray for pets; and as a granular form on turf and golf courses. 
Fipronil is a phenylpyrazole compound and was developed as a useful insecticide in the mid-1990s. It is effective against some insects such as the Colorado potato beetle and certain cotton pests that have become resistant to the existing insecticides. Fipronil is much more toxic to insects than to mammals, another advantage it has as an insecticide.

Fipronil is an insecticide approved for marketing in the year 1993. It is a member of the phenylpyrazole class of pesticides, which are principally chemicals with herbicidal effect and act as contact and stomach poisons. It is sparingly soluble in water and stable at room temperature for one year, but unstable in the presence of metal ion. On exposure to sunlight it produces a variety of metabolites such as fipronil-desulfinyl (MB 46513) which is extremely stable and 10 times more toxic than the parent compound (Hainzl et al., 1998). Fipronil noncompetitively antagonizes GABAA receptors as well as glutamateactivated chloride channels. Particularly, sulfone metabolite of fipronil blocks $\gamma$ aminobutyric acid and glutamate-activated chloride channels in mammalian and insect neurons (Zhao et al., 2005), consequently blocking the passage of chloride ions through the GABA and glutamate-gated chloride channel $(\mathrm{GluCl})$ receptors. This disrupts the insect central nervous system causing hyperexcitation of contaminated insects' nerves and muscles. Insect specificity of fipronil may come from a better efficacy on GABA receptor and also due the fact that $\mathrm{GluCl}$ channels does not exist in mammals.

Insect GABA receptors are structurally similar to vertebrate GABAA and GABAC receptors which together with glycine receptors (GlyR) are members of the ligandgated chloride channel family (Jentsch et al., 2002). These receptors have structural features that are common among all members of the ligand-gated ion channel superfamily.
Although GABA-gated chloride channels are expressed in the CNS of both vertebrates and invertebrates, fipronil has a considerably higher affinity for insect GABA receptors than vertebrate GABAA and GABAC receptors. This property is also thought to account for the low toxicity of fipronil in mammals relative to arthropods (Gant et al., 1998; Hainzl et al., 1998; Ratra et al., 2001; Tingle et al., 2003). However, fipronil can bind to mammalian GABAA and GABAC receptors (Ikeda et al., 2001). Its sulfone metabolites and fipronil desulfinyl, a product of photodegradation were reported to be more toxic to insects, mammals, fishes and birds than the parent compound.

\section{Health effects of pesticides on consumers}

Pesticides have improved the standard of human health by controlling vector-borne diseases, however, their long term and indiscriminate use has resulted in serious health effects. Human beings especially infants and children are highly vulnerable to deleterious effects of pesticides due to the non-specifi $c$ nature and inadequate application of pesticides. As the pesticide use has increased over the past few decades, the likelihood of exposure to these chemicals has also increased considerably. According to World Health Organization, each year, about $3,000,000$ cases of pesticide poisoning and 220, 000 deaths are reported in developing countries (Lah, 2011).

About 2.2 million people, mainly belonging to developing countries are at increased risk of exposure to pesticides (Hicks, 2013). Besides, some people are more susceptible to the toxic effects of pesticide than others, such as infants, young children, agricultural farm workers and pesticide applicators (Pesticides and Human Health n.d.). Pesticides enter the human body through ingestion, inhalation or penetration via skin (Spear, 1991). But the 
majority of people get affected via the intake of pesticide contaminated food. After crossing several barriers, they ultimately reach human tissues or storage compartments (Hayo and Werf, 1996). Although human bodies have mechanisms for the excretion of toxins, however, in some cases, it retains them through absorption in the circulatory system (Jabbar and Mallick 1994). Toxic effects are produced when the concentration of pesticide in the body increases far more than its initial concentration in the environment (Hayo and Werf, 1996).

\section{Cancer}

The studies on cancer analyze the risks associated with the consumption of specific products which have some pesticide residues. These consumption products include: fish ( $\mathrm{Li}$ et al., 2008), water (Buczynska and Szadkowska, 2005) seafood (Moon et al., 2009) and milk or other dairy products (Pandit and Sahu, 2002). In general these studies find a small but statistically significant association between cancer risks and some specific pesticide residues, such as DDT and DDD (dichlorodiphenyldichloroethane), but not for other organochlorines. Specifically PCBs (polychlorinated biphenyls) present a higher risk for consumers (Li et al., 2008).

The risk of pesticides to human health has been of public concern since the 1970s. The benefits of pesticide use then started being weighed against their costs, which led to research being conducted monetizing the benefits and the costs. Most of the early work was conducted in the US and after only a few studies were carried out in the 1980s, there was a rapid growth in the number of studies in the 1990s.

\section{Risks associated with pesticide use}

Risks associated with pesticide use have surpassed their beneficial effects. Pesticides have drastic effects on non-target species and affect animal and plant biodiversity, aquatic as well as terrestrial food webs and ecosystems. According to Majewski and Capel (1995), about 80-90 \% of the applied pesticides can volatilize within a few days of application (Majewski and Capel, 1995). It is quite common and likely to take place while using sprayers. The volatilized pesticides evaporate into the air and subsequently may cause harm to non-target organism. A very good example of this is the use of herbicides, which volatilise off the treated plants and the vapours are sufficient to cause severe damage to other plants (Straathoff, 1986). Uncontrolled use of pesticides has resulted in reduction of several terrestrial and aquatic animal and plant species. They have also threatened the survival of some rare species such as the bald eagle, peregrine falcon and osprey (Helfrich et al., 2009). Additionally, air, water and soil bodies have also being contaminated with these chemicals to toxic levels.

In conclusion, pesticides have proved to be a boon for the farmers as well as people all around the world by increasing agricultural yield and by providing innumerable benefits to society indirectly. But the issue of hazards posed by pesticides to human health and the environment has raised concerns about the safety of pesticides

\section{References}

Abu, M. T. 2005. Adverse impact of insecticides on the health of Palestinian farm workers in the Gaza Strip: a hematologic biomarker study. Int $\mathbf{J}$ Occup Environ Health. 11(2): 144-9.

Banerjee, B.D., Seth, V., Bhattacharya, A., Pasha, S.T. and Chakravorty, A.S. 1999. Biochemical effects of some pesticides on lipid peroxidation and free-radical scavenger Toxicol. Lett., 107, pp. 33-47 
Buczynska, A. and I. Szadkowska 2005. 'Identification of Heath Hazards to Rural Population Living near Pesticide Dump Sites in Poland'. International Journal of Occupational Medicine and Environmental Health 18(4), 331-339

Costa, C., Silva, S., Coelho, P., Roma-Torres, J., Teixeira, J.P., Mayan, O. 2007 Micronucleus analysis in a Portuguese population exposed Environ Sci Pollut Res to pesticides: preliminary survey. Int J Hyg Environ Health 210(34):415-418

Daniels, J.L., Olshan, A.F., Savitz, D.A. 1997. Pesticides and childhood cancers. Environ Health Perspect.; 105(10): 1068-77.

Delaplane, K.S. 2000. Pesticide usage in the United States: history, benefits, risks, and trends. Cooperative Extension Service. The University of Georgia, College of Agricultural and Environmental Sciences. Bulletin 1121. Reprinted November, 2000. http://pubs.caes.uga.edu/ caespubs/pubs/PDF/B1121.pdf

Engel, A. K., Fries, P., and Singer, W. 2001. Dynamic predictions: oscillations and synchrony in top-down processing. Nat. Rev. Neurosci. 2, 704-716

Ergene, S., Cavas, T., Celik,A., Koleli, N., Kaya, F. and Karahan, A. 2007. Monitoring of nuclear abnormalities in peripheral erythrocytes of three fish species from the Goksu Delta (Turkey): Genotoxic in relation to water pollution. Ecotoxicology, 16: 385-391

Figa-Talamanca, I., Traina, E. and Urbani, E. 2001 Occupational exposure to chemicals: recent evidence on male reproductive effects and biological markers. Occup Med (Lond); 51: 174 188.

Gant, D. B., Chalmers, A. E., Wolff, M. A., Hoffman, H. B. and Bushey, D. F. 1998.
Fipronil: action at the GABA receptor. Rev. Toxicol. 2: 147-156.

Gómez, A.S., Calderón-Segura, M.E. and Villalobos Pietrini, R. 2000. Biomonitoring of pesticides by plant metabolism: an assay base on the induction of sister-chromatid exchanges in human lymphocyte cultures by promutagen activation of Vicia faba. In: Biomonitors and biomarkers as indicators of environmental change. (F.M. Butterworth, A. Gunatilaka and M.E. Gonsebatt, Eds.). Plenum Press, New York, Vol. 2, pp. 439-455

Gupta, A., Singh, B., Parihar, N.S. and Bhatnagar, A. 1998. Pesticide residue in the farm gate samples of bottle gourd, cauliflower, cabbage and fenugreek at Jaipur. Pesticide Research Journal. 10: 86-90

Hainzl, D., Cole, L. M. and Casida, J. E. 1998. Mechanisms for selective toxicity of fipronil insecticide and its sulfone metabolite and desulfinyl photoproduction. Chem. Res.Toxicol. 11: 1529-1535

Hayo, M.G., Werf, V.D. 1996. Assessing the impact of pesticides on the environment. Agric Ecosyst Environ 60:81-96

Helfrich, L.A., Weigmann, D.L., Hipkins, P., Stinson, E.R. 2009. Pesticides and aquatic animals: a guide to reducing impacts on aquatic systems. In: Virginia Polytechnic Institute and State University. Available from https://pubs.ext.vt.edu/420/420013/420-013.html. Accessed Jan 17, 2015

Hicks,B.2013.Agricultural pesticides and human health. In: National Association of Geoscience Teachers. Available from http://serc.carleton.edu/NAGTWorksho ps/health/case_studies/pesticides. html. Accessed Jan 13, 2014

Ikeda, T., Zhao, X., Nagata, K., Kono, Y., 
Shono, T., Yeh, J. Z. and Narahashi, T. 2001. Fipronil modulation of gammaaminobutyric acid (A) receptors in rat dorsal root ganglion neurons. J. Pharmacol. Exp. Ther. 296: 914-921

Jabbar, A., Mallick, S. 1994. Pesticides and environment situation in Pakistan (Working Paper Series No. 19). Available from Sustainable Development Policy Institute (SDPI)

Jenner, P. 2001. Parkinson's disease, pesticides and mitochondrial disfuntion. Trends in Neuroscience 24: 245-246.

Jentsch, T. J., Stein, V., Weinreich, F. and Zdebik, A. A. 2002. Molecular structure and physiological function of chloride channels. Physiol. Rev. 82: 503-568

Khuder, S.A. and Mutgi, A.B. 1997. Metaanalyses of multiple myeloma and farming. Am J Ind Med 32:510-551

Lah, K. 2011.Effects of pesticides on human health. In: Toxipedia. Available from http://www.toxipedia.org/display/toxipe dia/Effects+of+Pesticides+on+Human+ Health. Accessed Jan 16, 2014

Macneale, K.H., Kiffney, P.M., Scholz, N.L. 2010. Pesticides, aquatic food webs, and the conservation of Pacific salmon. Front Ecol Environ 8:475-482

Majewski, M. Capel, P. 1995 Pesticides in the atmosphere: distribution, trends, and governing factors. Pesticides in the hydrologic system, vol 1. Ann Arbor Press Inc., Boca Raton, FL, p 118

Moon, H.B., H.S. Kim, M. Choi, Yu, J, Choi, H.G. 2009. 'Human health risk of polychlorinated biphenyls and organochlorine pesticides resulting from seafood consumption in South Korea, 2005- 2007'. Food and Chemical Toxicology 47(1), 1819-1825.

Muniz, J.F., McCauley, L., Scherer, J., Lasarev, M., Koshy, M., Kow, Y.W., Nazar-Stewart, V. and Kisby, G.E. 2008. Biomarkers of oxidative stress and DNA damage in agricultural workers: A pilot study. Toxicol Appl Pharmacol 227:97-107

Ojajarvi, I., Partanen, T., Ahlbom, A., Boffetta,P., Hakulinen, T. and Jourenkova, N. 2000. Occupational exposures and pancreatic cancer: A meta-analysis. Occup. Environ. Med., 7: 316-324

Pandit, G. and S. Sahu 2002. 'Assessment of risk to public health posed by persistent organochlorine pesticide residues in milk and milk products in Mumbai, India'. Journal of Environmental Monitoring 4(1), 182-185.

Panemangalore, M., Dowla, H.A. and Byers, M. 1999. Occupational exposure to agricultural chemicals: effect on the activities of some enzymes in the blood of farm worker. Intl. Arch. Environ. Hlth., 72(2): 94-98

Ratra, G. S., Kamita, S. G. and Casida, J. E. 2001. Role of the human GABAA receptor b3 subunit in insecticide toxicity. Toxicol. Appl. Pharmacol. 172: 233-240

Ritz B, Yu F. 2000. Parkinson's disease mortality and pesticide exposure in California 1984-1994. Int J Epidemiol 29:323-329

Spear, R. 1991. Recognised and possible exposure to pesticides. In: Hayes WJ, Laws ER (eds) Handbook of pesticide toxicology. Academic, San Diego, CA, pp 245-274

Straathoff, H. 1986. Investigations on the phytotoxic relevance of volatilization of herbicides. Mededelingen 51(2A):433438

Tingle, C. C., Rother, J. A., Dewhurst, C. F., Lauer, S. and King, W. J. 2003. Fipronil: environmental fate, ecotoxicology, and human health concerns. Rev. Environ. Contam. Toxicol. 176: 1-66

Undeger, U. and Basaran, N. 2002. Assessment of DNA damage in workers 
occupationally exposed to pesticide mixtures by alkaline comet assay. Archives of Toxicology 76: 430-6

Zahm, S. H., and Ward, M. H. 1998. Pesticides and childhood cancer. Environ. Health. Perspect. 106(suppl. 3):893-908
Zhao, X., Yeh, J. Z., Salgado,V. L. and Narahashi, T. 2005.Sulfone metabolite of fipronil blocks gamma aminobutyric acid- and glutamate-activated chloride channels in mammalian and insect neurons. J. Pharmacol. Exp. Ther., 314: 363-373.

\section{How to cite this article:}

Rajveer Kaur, Gurjot Kaur Mavi and Shweta Raghav. 2019. Pesticides Classification and Its Impact on Environment. Int.J.Curr.Microbiol.App.Sci. 8(03): 1889-1897.

doi: https://doi.org/10.20546/ijcmas.2019.803.224 